\title{
Uso da Água por Plantas de ARroz em Competição com Biótipos DE Echinochloa crusgalli RESISTENTE E SUSCETÍvel AO HERBICIDA QUINCLORAC ${ }^{1}$
}

\author{
Water Use by Rice Plants Under Competition with Echinochloa crusgalli Biotypes Resistant \\ and Susceptible to Quinclorac
}
CONCENÇO, G..$^{2}$, FERREIRA, E.A. ${ }^{2}$, ASPIAZU, I. ${ }^{2}$, SILVA, A.F. ${ }^{3}$, GALON, L. ${ }^{2}$, FERREIRA, F.A. ${ }^{4}$, SILVA, A.A. ${ }^{4}$ e ANDRES, A. ${ }^{5}$

\begin{abstract}
RESUMO - Objetivou-se com este trabalho avaliar as características associadas à eficiência de uso da água por plantas de arroz irrigado, quando sob competição com biótipos de capim-arroz resistente ou suscetivel ao herbicida quinclorac, em diferentes densidades. O experimento foi realizado em casa de vegetação, em delineamento de blocos casualizados e esquema fatorial 2 × 6 (dois biótipos e seis densidades de infestação), com quatro repetições. Os tratamentos consistiram em manter uma planta de arroz no centro da unidade experimental, competindo com $0,1,2,3,4$ ou 5 plantas do biótipo resistente ou suscetivel na periferia. Aos $50 \mathrm{DAE}$ (dias após a emergência) foram avaliadas a condutância estomática de vapores de água, a pressão de vapor na câmara subestomática, a temperatura da folha e a taxa transpiratória, sendo calculada ainda a eficiência do uso da água. As plantas foram coletadas junto à superficie do solo, acondicionadas em sacos de papel e secas em estufa $\left(70 \pm 1{ }^{\circ} \mathrm{C}\right)$ com circulação forçada de ar até massa constante, para obtenção da massa seca de planta. Os dados foram submetidos à análise de variância pelo teste F; em caso de significância, aplicou-se o teste de Duncan para avaliar o efeito da densidade de plantas e o teste da Diferença Minima Significativa (DMS) para diferenças entre as influências dos biótipos resistente e suscetivel sobre as plantas de arroz. Plantas de arroz foram afetadas pelo aumento no número de plantas de capim-arroz competindo com a cultura, mas não foram observadas diferenças na maioria das variáveis estudadas em função do biótipo com o qual essas plantas competiam. Variáveis-chave, como a eficiência do uso da água, foram mais afetadas quando as plantas de arroz competiam com plantas de capim-arroz do biótipo suscetivel ao herbicida quinclorac. Em condições de lavoura, essa característica pode não influenciar significativamente o desenvolvimento das plantas de arroz quando em interação com outros fatores.
\end{abstract}

Palavras-chave: capim-arroz, resistência, quinclorac, arroz irrigado

\begin{abstract}
The objective of this work was to evaluate the characteristics related to water use efficiency of rice plants, under competition with different densities of Echinochloa crusgalli plants. The trial was installed under greenhouse conditions, in a completely randomized block design, and factorial scheme $2 \times 6$ (two biotypes and six infestation densities), with four replications. The treatments consisted of one rice plant at the center of the plot, under competition with $0,1,2,3$, 4 or 5 plants of Echinochloa crusgalli, resistant or susceptible to quinclorac, at the periphery of the plot. Fifty days after emergence, water vapor stomatal conductance, sub-stomatal water pressure, leaftemperature and transpiration rate were evaluated, as well as water use efficiency. The plants were cut at the soil level and put into paper bags and dried at $70 \pm 1^{\circ} \mathrm{C}$ until dry mass stabilization. Data were analyzed by the F-test and, in case of significance, submitted to the DMRT test to
\end{abstract}

1 Recebido para publicação em 4.9.2008 e na forma revisada em 5.6.2009.

${ }^{2}$ Doutor em Fitotecnia, International Agronomist - Valmont Industries - USA, <gconcenco@yahoo.com.br>; ${ }^{3}$ Doutorando em Fitotecnia da Universidade Federal de Viçosa - UFV, bolsista CNPq; ${ }^{4}$ Professor, Dr., Dep. de Fitotecnia - DFT/UFV; ${ }^{5}$ Pesquisador da área de herbologia da Embrapa Clima Temperado, Pelotas-RS. 
evaluate the effect of increasing competition with Echinochloa over the rice plants, and to DMS test to compare the rice plants submitted to the biotypes at each competition level. Rice plants were more affected as the barnyardgrass density increased, but differences related to the biotype were not observed. Important variables, such as water use efficiency, were more affected when rice plants were under competition with plants of the susceptible biotype. Under field conditions, this characteristic may not be relevant to rice plant development, when interacted with other factors.

Keywords: barnyardgrass; resistance; quinclorac; irrigated rice.

\section{INTRODUÇÃO}

O capim-arroz é uma das mais importantes plantas daninhas da agricultura mundial, sendo relatada como planta competidora em mais de 36 culturas em 61 países (Norris et al., 2001). O controle dessa planta daninha nas lavouras de arroz irrigado tornou-se prática obrigatória, sendo realizado principalmente pelo método químico, utilizando herbicidas pré ou pós-emergentes seletivos à cultura (LopezMartinez et al., 1999), devido à praticidade e alta eficiência destes. No Brasil, o capim-arroz (Echinochloa spp.) aparece na grande maioria das lavouras do Rio Grande do Sul e Santa Catarina, destacando-se como uma das principais plantas daninhas da cultura do arroz (Ramírez et al., 2001). Os efeitos negativos de sua presença para a cultura incluem a alta capacidade de competição com as plantas de arroz por recursos limitantes, a dificuldade de controle, o aumento do custo de produção, o acamamento das plantas da cultura, a dificuldade de colheita, a depreciação da qualidade do produto, a hospedagem de pragas e a redução do valor comercial das áreas cultivadas (Kissmann \& Groth, 1997; Lopez-Martinez et al., 1999).

A principal forma de interferência que se estabelece entre capim-arroz e arroz irrigado é a competição pelos recursos luz e nutrientes, constituindo-se em um dos principais fatores limitantes da produtividade nas lavouras de arroz irrigado do Rio Grande do Sul e de Santa Catarina (Andres \& Machado, 2004; SOSBAI, 2005).

A competição de plantas daninhas pode afetar quantitativa e qualitativamente a produção, pois modifica a eficiência de aproveitamento dos recursos do ambiente, como água, luz e nutrientes (Sinclair et al., 1975; Melo et al., 2006), que se estabelece entre a cultura e as plantas de outras espécies existentes no local. Essa competição ocorre também entre indivíduos de uma mesma espécie ou entre biótipos predominantes na área, conforme constatado por Ferreira et al. (2008), verificando que biótipos de azevém resistentes ao glyphosate possuem menor capacidade competitiva do que os suscetiveis.

A eficiência do uso da água é caracterizada como a quantidade de água evapotranspirada por uma cultura para a produção de certa quantidade de matéria seca (Silva et al., 2007). Assim, culturas mais eficientes no uso da água produzem mais matéria seca por grama de água transpirada. A soja, por exemplo, necessita de $750 \mathrm{~g}$ de água por $\mathrm{g}$ de massa seca acumulada, enquanto o arroz irrigado necessita de $4.700 \mathrm{~g}$ de água por g de massa seca acumulada (Baptista et al., 2001). O uso mais eficiente da água está diretamente relacionado ao tempo de abertura estomática, pois, enquanto a planta absorve $\mathrm{CO}_{2}$ para a fotossintese, a água é perdida por transpiração com intensidade variável, dependendo do gradiente de potencial entre a superficie foliar e a atmosfera, seguindo uma corrente de potenciais hídricos (Pereira-Netto et al., 2002).

Uma das opções para melhorar a utilização do recurso água pode ser a escolha de cultivares mais eficientes quanto ao uso da água para produção da parte econômica - em especial, o arroz irrigado (Baptista et al., 2001), classificado como muito exigente quanto à água durante o ciclo (Noldin et al., 2001).

Quando plantas estão submetidas à alta competição, as características físiológicas do crescimento e desenvolvimento normalmente são alteradas, o que resulta em diferenças no aproveitamento dos recursos do ambiente, principalmente no uso da água, que influencia de modo direto a disponibilidade de $\mathrm{CO}_{2}$ no mesofilo foliar e a temperatura da folha e, 
consequentemente, a eficiência fotossintética da planta (Bunce, 1997).

Objetivou-se com este trabalho avaliar as características associadas à eficiência de uso da água por plantas de arroz irrigado quando sob competição com biótipos de capim-arroz resistente ou suscetivel ao herbicida quinclorac, em diferentes densidades, em casa de vegetação.

\section{MATERIAL E MÉTODOS}

O experimento foi instalado em casa de vegetação com irrigação por aspersão, em delineamento experimental de blocos casualizados em esquema fatorial $2 \times 6$, com quatro repetições. As unidades experimentais constaram de vasos de $13 \mathrm{~L}$ de substrato (mistura préelaborada de solo e terra vegetal, corrigida e adubada de acordo com análise de solo). Os tratamentos constaram de uma planta de arroz da variedade BRS-Pelota, que competia com número variável de plantas dos biótipos de capim-arroz resistente ou suscetivel ao herbicida quinclorac. No centro da unidade experimental foram semeadas três sementes de arroz, enquanto na periferia dessa unidade foram semeadas 10 sementes do biótipo resistente ou suscetivel ao herbicida quinclorac, de acordo com os tratamentos propostos.

As plântulas foram desbastadas aos 10 dias após a emergência (DAE). Os tratamentos consistiram em manter uma planta de arroz no centro da unidade experimental, variando na periferia as densidades de plantas de capim-arroz em $0,1,2,3,4$ ou 5 plantas do biótipo resistente ou suscetivel, de acordo com o tratamento. A área de semeadura da planta de arroz foi delimitada por um círculo de $5 \mathrm{~cm}$ de diâmetro por $2 \mathrm{~cm}$ de profundidade, que possibilitou a identificação da planta adulta, juntamente com os respectivos perfilhos, sem interferir na competição da planta central com as demais da periferia, tanto na parte aérea como no sistema de raízes.

As unidades experimentais foram mantidas equidistantes, de forma que a área de superficie disponível para o desenvolvimento das plantas correspondesse à área da unidade experimental. Aos 50 DAE foram realizadas as avaliações, no terço médio da primeira folha completamente expandida do perfilho principal das plantas de arroz. Foi utilizado um analisador de gases no infravermelho (IRGA), marca ADC, modelo LCA 4 (Analytical Development Co. Ltd, Hoddesdon, UK), em casa de vegetação aberta, permitindo livre circulação do ar. Cada bloco foi avaliado em um dia, entre 8 e 10 horas da manhã, de forma que mantivesse as condições ambientais homogêneas durante a avaliação.

As variáveis avaliadas foram condutância estomática de vapores de água (Gs $\left.-\mathrm{mol} \mathrm{m}^{-1} \mathbf{s}^{-1}\right)$, pressão de vapor na câmara subestomática $\left(E_{\text {an }}-\mathrm{mBar}\right)$, temperatura da folha $\left({ }^{\circ} \mathrm{C}\right)$ e taxa de transpiração $\left(\mathrm{E}-\mathrm{mol} \mathrm{H}_{2} \mathrm{O} \mathrm{m}^{-2} \mathbf{s}^{-1}\right)$, sendo calculada ainda a eficiência do uso da água (QUE - $\mathrm{mol} \mathrm{CO}_{2} \mathrm{~mol} \mathrm{H}_{2} \mathrm{O}^{-1}$ ) pela relação entre quantidade de $\mathrm{CO}_{2}$ fixado pela fotossintese e quantidade de água transpirada. Também se coletou a parte aérea das plantas; em seguida, o material foi seco em estufa de circulação forçada de ar a $60{ }^{\circ} \mathrm{C}$ até massa constante e pesado em balança analítica, onde se obteve a variável massa seca da parte aérea (MSPA).

Os dados foram submetidos à análise de variância pelo teste F; em caso de significância, efetuou-se o teste de Duncan para avaliar o efeito do aumento na densidade de plantas e o teste da Diferença Mínima Significativa (DMS) para avaliar diferenças entre as influências dos biótipos resistente e suscetivel sobre as plantas de arroz, em cada tratamento, a $5 \%$ de probabilidade.

\section{RESULTADOS E DISCUSSÃO}

O acúmulo de MSPA nas plantas de arroz, variedade BRS-Pelota, decresceu em função do aumento na intensidade de competição com plantas de capim-arroz, para ambos os biótipos estudados (Tabela 1). Quando a planta de arroz no centro da unidade experimental competia com uma planta de capim-arroz de ambos os biótipos, não foram observadas diferenças na MSPA em relação à testemunha livre de competição. Por outro lado, quando a planta de arroz competia com duas a cinco plantas de capimarroz, o acúmulo de MSPA foi similar entre esses tratamentos e inferior ao da testemunha, quando competindo com o biótipo resistente. O mesmo se observou para o biótipo suscetivel, ou seja, somente a partir de duas plantas do capim-arroz ocorreu diferença significativa. 
Tabela 1 - Massa seca de parte aérea (MSPA) de plantas de arroz irrigado, variedade BRS-Pelota, em função da competição com diferentes números de plantas de capimarroz dos biótipos resistente ou suscetível ao herbicida quinclorac

\begin{tabular}{|c|c|c|c|c|}
\hline \multicolumn{2}{|c|}{ Planta em competição } & Resistente $^{\underline{1}}$ & Suscetível $^{1 /}$ & Diferença $^{2}{ }^{\underline{\prime}}$ \\
\hline Arroz & Capim & \multicolumn{3}{|c|}{ MSPA (g por planta) } \\
\hline 1 & 0 & $0,69 \mathrm{a}$ & $0,89 \mathrm{a}$ & $-0,20 \mathrm{~ns}$ \\
\hline 1 & 1 & $0,79 \mathrm{a}$ & $1,08 \mathrm{a}$ & $-0,29 \mathrm{~ns}$ \\
\hline 1 & 2 & $0,25 \mathrm{~b}$ & $0,62 \mathrm{~b}$ & $-0,38 \mathrm{~ns}$ \\
\hline 1 & 3 & $0,27 \mathrm{~b}$ & $0,30 \mathrm{bc}$ & $-0,03 \mathrm{~ns}$ \\
\hline 1 & 4 & $0,22 \mathrm{~b}$ & $0,25 \mathrm{bc}$ & $-0,03 \mathrm{~ns}$ \\
\hline 1 & 5 & $0,17 \mathrm{~b}$ & $0,16 \mathrm{c}$ & $+0,01 \mathrm{~ns}$ \\
\hline
\end{tabular}

1/ Refere-se ao biótipo de capim-arroz com o qual a planta de arroz irrigado avaliada competia; ${ }^{2 /} \mathrm{ns}$ - não-significativo; *,** significativos a 5 e $1 \%$ de probabilidade, respectivamente, pelo teste da DMS.

Médias seguidas da mesma letra, na mesma coluna, não diferem pelo teste de Duncan a $5 \%$ de probabilidade.

Plantas de arroz que competiam com plantas de capim-arroz do biótipo resistente possibilitaram a estratificação em dois niveis quanto ao acúmulo de MSPA, ao passo que o biótipo suscetível ao herbicida quinclorac permitiu a disposição em três níveis. Não foram observadas diferenças quanto ao acúmulo de MSPA em plantas de arroz, em função da competição com o biótipo resistente ou com o suscetivel de capim-arroz, no mesmo nível de competição. Logo, pode-se inferir que o efeito negativo de plantas de capim-arroz dos biótipos sobre as plantas de arroz é similar e que, independentemente do biótipo presente na lavoura, o controle deve ser efetuado no mesmo momento.

A condutância estomática (Gs) de vapores de água das plantas de arroz não foi alterada em função do aumento no número de plantas de capim-arroz competindo com a cultura, tanto do biótipo resistente quanto do suscetivel ao herbicida quinclorac (Tabela 2). A condutância foliar é composta em pequena parte pela condutância cuticular da epiderme e, quando os estômatos estão abertos, pela Gs, que é controlada pelas células-guarda dos estômatos. Assim, a Gs é proporcional ao número, tamanho e diâmetro da abertura dos estômatos, características que dependem, além dos fatores já citados, também de outros fatores endógenos
Tabela 2 - Condutância estomática (Gs) de plantas de arroz irrigado, variedade BRS-Pelota, em função da competição com diferentes números de plantas de capimarroz dos biótipos resistente ou suscetível ao herbicida quinclorac

\begin{tabular}{|c|c|c|c|c|}
\hline \multicolumn{2}{|c|}{ Planta em competição } & Resistente $^{\mathrm{I}^{-}}$ & Suscetível $^{{ }^{1}}$ & Diferença $^{2}{ }^{-}$ \\
\hline Arroz & Capim & \multicolumn{3}{|c|}{ Gs $\left(\mathrm{mol} \mathrm{m}^{-1} \mathrm{~s}^{-1}\right)$} \\
\hline 1 & 0 & $0,10 \mathrm{a}$ & $0,11 \mathrm{a}$ & $-0,01 \mathrm{~ns}$ \\
\hline 1 & 1 & $0,09 \mathrm{a}$ & $0,10 \mathrm{a}$ & $-0,01 \mathrm{~ns}$ \\
\hline 1 & 2 & $0,08 \mathrm{a}$ & $0,09 \mathrm{a}$ & $-0,01 \mathrm{~ns}$ \\
\hline 1 & 3 & $0,08 \mathrm{a}$ & $0,10 \mathrm{a}$ & $-0,02 \mathrm{~ns}$ \\
\hline 1 & 4 & $0,09 \mathrm{a}$ & $0,09 \mathrm{a}$ & $0 \mathrm{~ns}$ \\
\hline 1 & 5 & $0,09 \mathrm{a}$ & $0,08 \mathrm{a}$ & $+0,01 \mathrm{~ns}$ \\
\hline
\end{tabular}

1/ Refere-se ao biótipo de capim-arroz com o qual a planta de arroz irrigado avaliada competia; ${ }^{2 /} \mathrm{ns}$ - não-significativo; $*, * *$ significativos a 5 e $1 \%$ de probabilidade, respectivamente, pelo teste da DMS.

Médias seguidas da mesma letra, na mesma coluna, não diferem pelo teste de Duncan a $5 \%$ de probabilidade.

e ambientais (Brodribb \& Holbrook, 2003). O valor médio da condutância estomática observado nos tratamentos foi de 0,09, e a diferença observada entre plantas de arroz que competiam com o biótipo resistente e as que competiam com o suscetivel foi próxima a $0,01 \mathrm{~mol} \mathrm{~m}^{-1} \mathbf{s}^{-1}$. Como o arroz é uma planta melhorada, portanto bastante homogênea, pode-se inferir que a imposição da competição não foi suficiente para sobrepassar a importância dos demais fatores na determinação da Gs.

A pressão de vapor na câmara subestomática $\left(E_{\text {an }}\right)$ das folhas de arroz foi menor quando em alta intensidade de competição com as plantas de capim-arroz, tanto resistente como suscetivel ao quinclorac (Tabela 3). A pressão de vapor nas folhas de arroz foi inferior à da testemunha livre de infestação, quando competindo com quatro ou cinco plantas do biótipo resistente, ou com cinco plantas de capimarroz do biótipo suscetível. A $\mathrm{E}_{\text {an }}$ está diretamente relacionada ao status hídrico da planta e à dinâmica de fluxo de vapor de água (Bunce, 1997). Mesmo em uma folha transpirando rapidamente, a umidade relativa na câmara poderá exceder $95 \%$ e o potencial hídrico resultante pode estar próximo de zero, incrementando as trocas com o meio ambiente, que possui potencial hídrico muito negativo 
(Cochard et al., 2002). Nessas condições, a pressão de vapor seria igual à pressão de vapor de saturação na temperatura da folha. Dessa forma, a $\mathrm{E}_{\mathrm{an}}$ é controlada pelo nivel de umidade e temperatura da folha e atua sobre a condutância estomática de vapores de água (Gs) e sobre a transpiração (E). Além disso, de maneira geral, menores valores de $\mathrm{E}_{\text {an }}$ influenciam a Gs, que por sua vez pode afetar a eficiência do uso da água pela planta (Sinclair et al., 1975). Também não foram observadas diferenças entre plantas de arroz que competiram com os biótipos resistente ou suscetível, em nenhum dos tratamentos avaliados.

O metabolismo vegetal faz com que, via de regra, a temperatura da folha seja superior à temperatura do ar ao seu redor. Assim, incrementos no metabolismo podem ser indiretamente aferidos em função da temperatura da folha. Normalmente essa diferença fica em torno de um ou dois graus, mas em casos extremos pode exceder a $5{ }^{\circ} \mathrm{C}$ (Drake \& Salisbury, 1972; Atkin et al., 2000). A temperatura da folha das plantas de arroz não foi alterada em função do aumento na intensidade de competição com plantas de capim-arroz do biótipo resistente ao herbicida (Tabela 4). Por outro lado, quando a planta de arroz competiu com cinco plantas do biótipo suscetivel, apresentou temperatura inferior à observada nos demais tratamentos. Isso se deve, pelo menos em parte,

Tabela 3 - Pressão de vapor na câmara subestomática $\left(\mathrm{E}_{\mathrm{an}}\right)$ de arroz irrigado, variedade BRS-Pelota, em função da competição com diferentes números de plantas de capim-arroz dos biótipos resistente ou suscetível ao herbicida quinclorac

\begin{tabular}{|c|c|c|c|c|}
\hline \multicolumn{2}{|c|}{ Planta em competição } & Resistente $^{\underline{1}}$ & Suscetível $^{1 /}$ & Diferença $^{2}{ }^{2}$ \\
\hline Arroz & Capim & \multicolumn{3}{|c|}{$\mathrm{E}_{\mathrm{an}}(\mathrm{mBar})$} \\
\hline 1 & 0 & $16,1 \mathrm{a}$ & $16,0 \mathrm{a}$ & $+0,1 \mathrm{~ns}$ \\
\hline 1 & 1 & $14,8 \mathrm{ab}$ & $14,7 \mathrm{ab}$ & $+0,1 \mathrm{~ns}$ \\
\hline 1 & 2 & $14,7 \mathrm{ab}$ & $15,1 \mathrm{ab}$ & $-0,4 \mathrm{~ns}$ \\
\hline 1 & 3 & $14,4 \mathrm{ab}$ & $15,2 \mathrm{ab}$ & $-0,8 \mathrm{~ns}$ \\
\hline 1 & 4 & $13,8 \mathrm{~b}$ & $14,7 \mathrm{ab}$ & $-0,9 \mathrm{~ns}$ \\
\hline 1 & 5 & $13,3 \mathrm{~b}$ & $13,6 \mathrm{~b}$ & $-0,3 \mathrm{~ns}$ \\
\hline
\end{tabular}

1/ Refere-se ao biótipo de capim-arroz com o qual a planta de arroz irrigado avaliada competia; ${ }^{2 /} \mathrm{ns}$ - não-significativo; $*, * *$ significativos a 5 e $1 \%$ de probabilidade, respectivamente, pelo teste da DMS.

Médias seguidas da mesma letra, na mesma coluna, não diferem pelo teste de Duncan a $5 \%$ de probabilidade. ao menor metabolismo da planta de arroz, em razão da menor captação de luz ocasionada pelo sombreamento causado pelas plantas de capim-arroz. Foram constatadas ainda diferenças entre as plantas que competiram com quatro ou cinco plantas dos distintos biótipos de capim-arroz, sendo observada maior temperatura da folha das plantas de arroz que competiram com o biótipo de capim-arroz resistente, provavelmente também devido à maior captação de luz e ao maior metabolismo.

A taxa transpiratória das plantas de arroz foi alterada em função da intensidade de competição dos biótipos de capim-arroz resistente e suscetivel ao herbicida quinclorac (Tabela 5). Quando competindo com o biótipo resistente, somente a menor intensidade de competição não diferiu da testemunha livre de infestação. Em patamar inferior, localizaramse as densidades de duas a quatro plantas de capim-arroz, que não diferiram entre si e foram superiores ao tratamento em que a planta de arroz competiu com cinco plantas de capimarroz. Quando as plantas de arroz competiram com as de capim-arroz do biótipo suscetivel, o comportamento foi similar ao da competição com plantas do biótipo resistente, também sendo possivel a estratificação em três niveis. No entanto, diferenças quanto à testemunha não infestada foram observadas somente sob maior intensidade de competição.

Tabela 4 - Temperatura da folha $\left(\mathrm{T}_{\text {leaf }}\right)$ de plantas de arroz irrigado, variedade BRS-Pelota, em função da competição com diferentes números de plantas de capim-arroz dos biótipos resistente ou suscetível ao herbicida quinclorac

\begin{tabular}{|c|c|c|c|c|}
\hline \multicolumn{2}{|c|}{ Planta em competição } & Resistente $^{{ }^{1 /}}$ & ${\text { Suscetível }{ }^{1 /}}^{-}$ & Diferença $^{2 /}$ \\
\hline Arroz & Capim & \multicolumn{3}{|c|}{$\mathrm{T}_{\text {leaf }}\left({ }^{\circ} \mathrm{C}\right)$} \\
\hline 1 & 0 & $24,5 \mathrm{a}$ & $24,5 \mathrm{a}$ & $0 \mathrm{~ns}$ \\
\hline 1 & 1 & $23,9 \mathrm{a}$ & $23,9 \mathrm{ab}$ & $0 \mathrm{~ns}$ \\
\hline 1 & 2 & $23,8 \mathrm{a}$ & $24,0 \mathrm{ab}$ & $-0,2 \mathrm{~ns}$ \\
\hline 1 & 3 & $24,7 \mathrm{a}$ & $24,2 \mathrm{ab}$ & $+0,5 \mathrm{~ns}$ \\
\hline 1 & 4 & $24,1 \mathrm{a}$ & $23,1 \mathrm{ab}$ & $+1,0 *$ \\
\hline 1 & 5 & $23,4 \mathrm{a}$ & $22,3 \mathrm{~b}$ & $+1,1^{*}$ \\
\hline
\end{tabular}

1/ Refere-se ao biótipo de capim-arroz com o qual a planta de arroz irrigado avaliada competia; ${ }^{2 /} \mathrm{ns}$ - não-significativo; ${ }^{*}, * *$ significativos a 5 e $1 \%$ de probabilidade, respectivamente, pelo teste da DMS. Médias seguidas da mesma letra, na mesma coluna, não diferem pelo teste de Duncan a $5 \%$ de probabilidade. 
Tabela 5 - Taxa transpiratória (E) de plantas de arroz irrigado, variedade BRS-Pelota, em função da competição com diferentes números de plantas de capim-arroz dos biótipos resistente ou suscetível ao herbicida quinclorac

\begin{tabular}{|c|c|c|c|c|}
\hline \multicolumn{2}{|c|}{ Planta em competição } & Resistente $^{1 /}$ & Suscetível $^{1 /}$ & Diferença $^{2 /}$ \\
\hline Arroz & Capim & \multicolumn{3}{|c|}{$\mathrm{E}\left(\mathrm{mol} \mathrm{H}_{2} \mathrm{O} \mathrm{m}^{-2} \mathrm{~s}^{-1}\right)$} \\
\hline 1 & 0 & $1,75 \mathrm{a}$ & $1,81 \mathrm{a}$ & $-0,06 \mathrm{~ns}$ \\
\hline 1 & 1 & $1,51 \mathrm{ab}$ & $1,62 \mathrm{ab}$ & $-0,11 \mathrm{~ns}$ \\
\hline 1 & 2 & $1,45 \mathrm{~b}$ & $1,70 \mathrm{ab}$ & $-0,25^{*}$ \\
\hline 1 & 3 & $1,38 \mathrm{~b}$ & $1,61 \mathrm{ab}$ & $-0,23^{*}$ \\
\hline 1 & 4 & $1,32 \mathrm{~b}$ & $1,39 \mathrm{~b}$ & $-0,07 \mathrm{~ns}$ \\
\hline 1 & 5 & $1,25 \mathrm{c}$ & $1,27 \mathrm{c}$ & $-0,07 \mathrm{~ns}$ \\
\hline
\end{tabular}

1/ Refere-se ao biótipo de capim-arroz com o qual a planta de arroz irrigado avaliada competia; ${ }^{2 /} \mathrm{ns}$ - não-significativo; *,** significativos a 5 e $1 \%$ de probabilidade, respectivamente, pelo teste da DMS.

Médias seguidas da mesma letra, na mesma coluna, não diferem pelo teste de Duncan a $5 \%$ de probabilidade.

Nas menores e nas maiores intensidades de competição, as plantas de arroz não diferiram na taxa transpiratória em função do biótipo de capim-arroz com o qual competiam (Tabela 6). Nas intensidades moderadas - duas ou três plantas de capim-arroz competindo com uma de arroz - foram observados maiores valores de transpiração para plantas que estavam na presença do biótipo de capim-arroz suscetivel ao herbicida quinclorac. Como E depende diretamente de Gs e $\mathrm{E}_{\mathrm{an}}$, que por sua vez também são afetados por fatores ambientais, pode-se inferir que o biótipo suscetivel apresenta a capacidade de causar maior sombreamento nas plantas de arroz, o que poderia resultar em menor radiação incidente e menor transpiração, embora isso não implique necessariamente que essas plantas sejam mais eficientes no uso da água.

O declínio de transpiração está associado ao fechamento dos estômatos, e variações na abertura estomática causam alterações no potencial hídrico, por atuarem sobre a $\mathrm{E}$ (Brodribb \& Hill, 2000). A planta tende a fechar os estômatos quando os niveis de luz estão abaixo da radiação fotossinteticamente ativa, ou para evitar o estresse hídrico (Cochard et al., 2002). Todos esss parâmetros estão ligados numa relação de custo/benefício, pois a $\mathrm{E}$ também é um mecanismo de diminuição da
Tabela 6 - Eficiência do uso da água (WUE) de plantas de arroz irrigado, variedade BRS Pelota, em função da competição com diferentes números de plantas de capim-arroz dos biótipos resistente ou suscetível ao herbicida quinclorac

\begin{tabular}{|c|c|c|c|c|}
\hline \multicolumn{2}{|c|}{ Planta em competição } & Resistente $^{1 /}$ & Suscetível $^{1 /}$ & Diferença $\mathrm{a}^{2 /}$ \\
\hline Arroz & Capim & \multicolumn{3}{|c|}{ WUE $\left(\mathrm{mol} \mathrm{CO} \mathrm{mol} \mathrm{H}_{2} \mathrm{O}^{-1}\right)$} \\
\hline 1 & 0 & $4,33 \mathrm{a}$ & $4,33 \mathrm{a}$ & $0 \mathrm{~ns}$ \\
\hline 1 & 1 & $4,44 \mathrm{a}$ & $4,33 \mathrm{a}$ & $+0,11 \mathrm{~ns}$ \\
\hline 1 & 2 & $4,48 \mathrm{a}$ & $3,76 \mathrm{~b}$ & $+0,72 *$ \\
\hline 1 & 3 & $4,32 \mathrm{a}$ & $3,77 \mathrm{~b}$ & $+0,55 *$ \\
\hline 1 & 4 & $4,20 \mathrm{a}$ & $3,90 \mathrm{~b}$ & $+0,30 \mathrm{~ns}$ \\
\hline 1 & 5 & $4,32 \mathrm{a}$ & $3,82 \mathrm{~b}$ & $+0,50 *$ \\
\hline
\end{tabular}

1/ Refere-se ao biótipo de capim-arroz com o qual a planta de arroz irrigado avaliada competia; ${ }^{2 /} \mathrm{ns}$ - não-significativo; ${ }^{*}, * *$ significativos a 5 e $1 \%$ de probabilidade, respectivamente, pelo teste da DMS.

Médias seguidas da mesma letra, na mesma coluna, não diferem pelo teste de Duncan a $5 \%$ de probabilidade.

temperatura da folha. Os processos de transpiração e captura de $\mathrm{CO}_{2}$ só ocorrem quando os estômatos estão abertos, bem como a Gs. Devido ao calor latente de evaporação (calor efetivamente usado para "aquecer" a água e possibilitar a evaporação), a transpiração tem um poderoso efeito resfriador, importante na regulação da temperatura da folha (Farquhar \& Raschke, 1978).

A eficiência do uso da água (WUE) representa a quantidade de $\mathrm{CO}_{2}$ fixado para a produção de matéria seca em função da quantidade de água transpirada (Silva et al., 2007). A eficiência do uso da água pelas plantas de arroz não foi afetada quando estas competiram com as plantas de capim-arroz do biótipo resistente (Tabela 6). Por sua vez, sob competição com plantas do biótipo suscetivel, a planta de arroz no centro da parcela foi menos eficiente no uso da água a partir de duas plantas de capim-arroz por unidade experimental. Essa diferença foi observada também entre biótipos no mesmo tratamento, nos maiores niveis de competição.

Além do exposto, E e $\mathrm{E}_{\text {an }}$ estão intimamente relacionadas, podendo se considerar que uma responde pela outra. Gs e E também estão correlacionadas, uma vez que a transpiração é determinante primária do balanço de 
energia e status hídrico da planta (Sinclair et al., 1975). A E é determinada principalmente por Gs e duas variáveis físicas: radiação solar e déficit de saturação atmosférica (Raschke \& Zeevaart, 1976; Hunt et al., 1985). Uma vez que a Gs não foi alterada, é prudente atribuir as alterações na $\mathrm{E}$ à radiação, em função principalmente do sombreamento ocasionado pelas plantas de capim-arroz, que são plantas $\mathrm{C}_{4} \mathrm{e}$, portanto, de rápido crescimento sob temperaturas relativamente elevadas e que também apresentam maior eficiência do uso da água que plantas de arroz, de metabolismo $\mathrm{C}_{3}$.

De maneira geral, observa-se que as plantas de arroz foram afetadas em função do aumento no número de plantas de capim-arroz competindo com a cultura, porém não foram observadas diferenças na maioria das variáveis estudadas em função do biótipo com o qual estas plantas competiam. Por outro lado, variáveis-chave, como a eficiência do uso da água, foram mais afetadas quando as plantas de arroz competiam com plantas de capim-arroz do biótipo suscetível ao herbicida quinclorac. Em condições de lavoura, essa característica pode não influenciar significativamente o desenvolvimento das plantas de arroz quando em interação com outros fatores.

\section{LITERATURA CITADA}

ANDRES, A.; MACHADO, S. L. O. Plantas daninhas em arroz irrigado. In: GOMES, A. S.; MAGALHÃES JR., A. M. (Eds.). Arroz irrigado no Sul do Brasil. Brasília: Embrapa Informação Tecnológica, 2004. p. 457-546.

ATKIN, O. K. et al. Leaf respiration of snow gum in the light and dark. Interactions between temperature and irradiance Plant Physiol., v. 122, n. 3, p. 915-923, 2000.

BAPTISTA, J. M. et al. Programa nacional para o uso eficiente da água. Lisboa: Instituto Superior de Agronomia, 2001. 212 p.

BRODRIBB, T. J.; HILL, R. S. Increases in water potential gradient reduce xylem conductivity in whole plants. Evidence from a low-pressure conductivity method. Plant Physiol., v. 123, n. 3 , p. $1021-1028,2000$

BRODRIBB, T. J.; HOLBROOK, N. M. Stomatal closure during leaf dehydration, correlation with other leaf physiological traits. Plant Physiol., v. 132, n. 4, p. $2166-2173,2003$.
BUNCE, J. A. Does transpiration control stomatal responses to water vapour pressure deficit? Plant, Cell Environ., v. 20, n. 1, p. 131-135, 1997.

COCHARD, H. et al. Unraveling the effects of plant hydraulics on stomatal closure during water stress in walnut. Plant Physiol., v. 128, p. 282-290, 2002.

DRAKE, B. G.; SALISBURY, F. B. Aftereffects of low and high temperature pretreatment on leaf resistance, transpiration, and leaf temperature in Xanthium. Plant Physiol., v. 50, n. 1, p. 572-575, 1972.

FARQUHAR, G. D.; RASCHKE, K. On the resistance to transpiration of the sites of evaporation within the leaf. Plant Physiol., v. 61, n. 6, p. 1000-1005, 1978.

FERREIRA, E. A. et al. Potencial competitivo de biótipos de azevém (Lolium multiflorum). Planta Daninha, v. 26, n. 2 , p. 261-269, 2008.

HUNT, E. R. et al. Effects of nitrate application on Amaranthus powellii Wats II. Stomatal response to vapor pressure difference is consistent with optimization of stomatal conductance. Plant Physiol., v. 79, n. 3, p. 614-618, 1985.

KISSMANN, K. G.; GROTH, D. Plantas infestantes e nocivas. 2.ed. São Paulo: BASF, 1997. Tomo I. 825 p.

LOPEZ-MARTINEZ, N. et al. Molecular markers indicate intraspecific variation in the control of Echinochloa spp. with quinclorac. Weed Sci., v. 47, n. 3, p. 310-315, 1999.

MELO, P. T. B. S. et al. Comportamento de populações de arroz irrigado em função das proporções de plantas originadas de sementes de alta e baixa qualidade fisiológica. R. Bras. Agroci., v. 12, n. 1, p. 37-43, 2006.

NOLDIN, J. A. et al. Persistência do herbicida clomazone no solo e na água quando aplicado na cultura do arroz irrigado, sistema pré-germinado. Planta Daninha, v. 19, n. 3, p. 401-408, 2001.

NORRIS, R. F. et al. Spatial arrangement, density, and competition between barnyardgrass and tomato: I. Crop growth and yield. Weed Sci., v. 49, n. 1, p. 61-68, 2001.

PEREIRA-NETTO, A. B. Crescimento e desenvolvimento. In: WACHOWICZ, C. M.; CARVALHO, R. I. N. (Eds.) Fisiologia vegetal - produção e pós-colheita. Curitiba: Champagnat, 2002. p. 17-42.

RAMÍREZ, H.; MENEZES, V. G.; MARIOT, C. H. P Controle de capim-arroz com o herbicida nominee em mistura com gamit na cultura do arroz irrigado. In: CONGRESSO BRASILEIRO DE ARROZ IRRIGADO, 2.; REUNIÃO DA CULTURA DO ARROZ IRRIGADO, 24., 2001, Porto Alegre. Anais... Porto Alegre: Instituto Rio-Grandense do Arroz, 2001. p. 528-530. 
RASCHKE, K.; ZEEVAART, J. A. D. Abscisic acid content, transpiration, and stomatal conductance as related to leaf age in plants of Xanthium strumarium L. Plant Physiol., v. 58, n. 2 , p. $169-174,1976$.

SILVA, A. A. et al. Competição entre plantas daninhas e culturas. In: SILVA, A. A.; SILVA, J. F. (Eds.). Tópicos em manejo de plantas daninhas. Viçosa, MG: Universidade Federal de Viçosa, 2007. p. 17-61.
SINCLAIR, T. R. et al. Water use efficiency of field-grown maize during moisture stress. Plant Physiol., v. 56, n. 2, p. $245-249,1975$.

SOCIEDADE SUL-BRASILEIRA DE ARROZ IRRIGADO - SOSBAI. Arroz irrigado: Recomendações técnicas da pesquisa para o Sul do Brasil. Santa Maria: Universidade Federal de Santa Maria, 2005. 159 p. 